\title{
HDAC2 Gene Mutation
}

National Cancer Institute

\section{Source}

National Cancer Institute. HDAC2 Gene Mutation. NCI Thesaurus. Code C154230.

A change in the nucleotide sequence of the HDAC2 gene. 